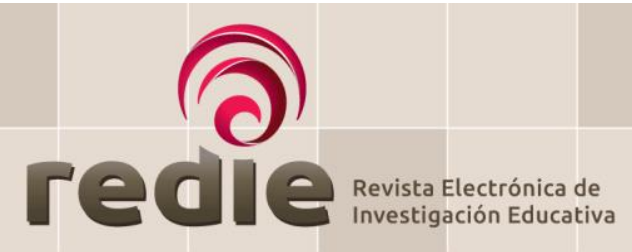

ISSN: $1607-4041$

https://redie.uabc.mx

Vol. 23, 2021/e20

\title{
Microblogging en escenarios curriculares universitarios: el uso de Twitter más allá del encargo docente
}

\section{Microblogging in Educational Settings in College: Use of Twitter Beyond Teacher Assignments}

\author{
Santiago Tejedor (1) https://orcid.org/0000-0002-5539-9800 \\ Óscar Coromina (2) https://orcid.org/0000-0002-6306-4154 \\ Gil Pla-Campas (3) https://orcid.org/0000-0003-4717-6401 \\ (1) Universidad Autónoma de Barcelona \\ (2) Universidad de Malmö \\ (3) Universidad de Vic-Universidad Central de Cataluña \\ (Recibido: 11 de noviembre de 2019; Aceptado para su publicación: 20 de abril de 2020)
}

Cómo citar: Tejedor, S., Coromina, O. y Pla-Campas, G. (2021). Microblogging en escenarios curriculares universitarios: el uso de Twitter más allá del encargo docente. Revista Electrónica de Investigación Educativa, 23, e20, 1-13.

https://doi.org/10.24320/redie.2021.23.e20.3565

\section{Resumen}

El impacto de Twitter se percibe de forma contundente en diferentes ámbitos del desempeño profesional y cotidiano. Combinando métodos cuantitativos y cualitativos se analiza cómo los jóvenes universitarios crean contenidos en Twitter desde el entorno académico, y cómo perciben esta actividad. Para ello se conformó una muestra intencional de tres grupos de estudiantes, se recolectó una muestra de 10291 tuits publicados y se desarrolló un grupo focal por cada grupo universitario. Entre otros aspectos, el trabajo evidencia que los estudiantes priorizan las exigencias y directrices académicas y señalan que la utilización que hacen de la plataforma varía en función de si se trata, o no, de un encargo académico.

Palabras clave: educación superior, competencia mediática, redes sociales

\section{Abstract}

The impact of Twitter can be strongly felt across a number of areas of professional and day-to-day life. By combining quantitative and qualitative methods, this article analyzes how young college students create content on Twitter in an academic setting, and how they perceive this content creation. To this end, a purposive sample of three groups of students was formed, a sample of 10,291 published tweets was collected, and a focus group was set up for each group of students. Among other findings, this study shows that students prioritize academic instructions and requirements and report that the way they use the platform depends on whether it is for an academic assignment or not. 


\section{Introducción}

Las redes sociales, concebidas como plataformas donde "todos los miembros de la comunidad saben, conocen y actúan en forma previsible y pertinente" (Galindo, 2010, p. 3) poseen un potencial educativo de gran valor. La "ecología" de medios incide en la capacidad de los avances tecnológicos para generar ambientes que, a su vez, impactan y poseen efectos sobre los propios usuarios (Scolari, 2012, 2013). De este modo, se plantea la necesidad de analizar el nuevo entorno edu-comunicativo, presidido por el crecimiento de las redes sociales (Castells, 2003), y de analizar las transformaciones que éstas introducen en diferentes ámbitos de la sociedad (Barabási y Bonabeau, 2003), especialmente el educativo. Trabajos como los de Roblyer et al. (2010) y Singh et al. (2015) han incidido en el impacto de estas plataformas en los procesos formativos a nivel general. La investigación de Jones et al. (2010), centrada en la utilización que el alumnado realizaba de las plataformas colaborativas a partir de una muestra integrada por estudiantes de cinco universidades inglesas, cuestiona que el término "nativos digitales" pueda considerarse como una categoría que aglutine a un grupo con las mismas habilidades técnicas y la misma competencia crítica en el uso de plataformas digitales. Por ello resulta de interés analizar cómo los usuarios más jóvenes (tanto los que integran la Generación Y como la Generación Z) utilizan sus redes sociales, especialmente Twitter, en el ámbito educativo, conectando escenarios de uso informal de las herramientas con otros de tipo formal o académico.

Los trabajos desarrollados confieren una importancia destacada al rol que las redes sociales poseen en el día a día de los usuarios. Un estudio de la Universidad de Pittsburgh advierte del incremento del riesgo de aislamiento entre estos jóvenes a medida en que se amplía el tiempo invertido en utilizar las redes sociales (Primack et al. 2017). Por su parte, en The Common Sense Census: Media Use by Tweens and Teens, Rideout (2015) señalaba que los adolescentes (de 13 a 18 años) invertían diariamente alrededor de nueve horas consumiendo medios digitales; mientras que los preadolescentes (de 8 a 12 años) dedicaban cerca de seis horas. No obstante, esta investigación, realizada entre 2658 jóvenes, aseguraba que para los jóvenes escuchar contenidos musicales o ver televisión eran actividades más demandadas que el envío de mensajes de texto o el acceso a redes sociales.

El informe Connected Life (KANTAR TNS, 2017), que ha reunido actitudes y comportamientos digitales de 60500 internautas de 50 países, apunta que los internautas dedican una media de tres horas diarias a consultar internet a través de dispositivos como móviles o tabletas. Según este trabajo, los internautas menores de 25 años invierten una media de cuatro horas y media. En este escenario, la investigación indica que el tiempo dedicado al uso de redes sociales es de casi dos horas al día. En Europa, el informe Children and parents: Media use and attitudes report (Ofcom, 2015) señala que en un período de cinco años (de 2010 a 2015) la franja de tiempo que los usuarios de 12 a 15 años dedican a navegar por la red se ha duplicado. El número de horas ha pasado, semanalmente, de 8 a 18.9 horas. El estudio señala que el $74 \%$ de estos usuarios posee perfiles en estas plataformas y alerta de un claro descenso de la capacidad de pensamiento crítico. Este aspecto está estrechamente vinculado con el peligro que significa la incapacidad de los jóvenes usuarios para salvaguardar su privacidad en internet y adquirir una alfabetización digital y mediática (Pérez y Tejedor, 2016).

En este escenario, Twitter se caracteriza por ser una plataforma qua aúna características de la mensajería instantánea, redes sociales y microblogging. La segunda edición del IMS Mobile in Latam Study (ComScore, 2016), que presenta un informe sobre tendencias en consumo digital y uso de aplicaciones móviles, señala que las plataformas más utilizadas son WhatsApp, YouTube, Facebook, Facebook Messenger, Google Maps, Instagram y Twitter. Junto al nivel de uso, las plataformas más valoradas entre los usuarios de la red son Instagram, WhatsApp, YouTube, Facebook, Facebook Messenger, Google Maps y Twitter (ComScore, 2016). En el caso de España, las plataformas sociales que poseen un mayor grado de uso WhatsApp (88\%), Facebook (87\%), Youtube (68\%), Instagram (54\%) y Twitter (50\%), según establece el informe de IAB (2019).

El presente estudio investiga hasta qué punto los estudiantes priorizan las exigencias/directrices académicas en escenarios curriculares y el uso que hacen de los recursos narrativos de la plataforma de microblogging Twitter. 
a) Redes sociales y sus usos. Las redes sociales han sido objeto de un amplio número de estudios que analizan aspectos vinculados con las características de los procesos comunicativos, el tipo de contenidos generados y compartidos, y los hábitos de uso de los usuarios que participan en las mismas, entre otros aspectos. Autores como Boyd (2007) y O'Keeffe y Clarke-Pearson (2011), entre otros, han incidido en las oportunidades que pueden obtener los usuarios de su interacción en las plataformas dialógicas. En este ámbito, el nuevo perfil de usuario de internet -especialmente, de los integrantes de la denominada Generación Y o millenials- ha sido objeto de un gran número de estudios y trabajos académicos. En la tabla 1 se presenta un resumen de los principales estudios que, desde enfoques cercanos al de la presente investigación, describe los principales resultados de la última década con relación al estudio de jóvenes y uso de redes sociales. Este resumen, así como la revisión bibliográfica realizada, denota que los trabajos sobre cómo los jóvenes universitarios utilizan las redes sociales se han basado en enfoque generales y evidencia la necesidad de que haya un trabajo sobre cuestiones de índole más específica.

Tabla 1. Principales estudios sobre redes y jóvenes

\begin{tabular}{|c|c|c|c|}
\hline Estudio & Año & Contexto & Principales conclusiones \\
\hline $\begin{array}{l}\text { Uso de las redes sociales por los } \\
\text { estudiantes de Comunicación de } \\
\text { Iberoamérica (Universidad de Murcia) }\end{array}$ & 2011 & España & $\begin{array}{l}\text { Destacada presencia del alumnado de comunicación } \\
\text { en las redes sociales, pero con un escaso uso } \\
\text { informativo. }\end{array}$ \\
\hline $\begin{array}{l}\text { State of the news media: Overview } \\
\text { (Pew Research Centre) }\end{array}$ & 2015 & EEUU & $\begin{array}{l}\text { Detección de una profunda brecha generacional en } \\
\text { el consumo de noticias a través de los canales } \\
\text { interactivos y de la televisión. } \\
\text { Facebook como red de acceso a información } \\
\text { política. } \\
\text { Casi la mitad de los usuarios de redes sociales } \\
\text { generaba y compartía contenidos. }\end{array}$ \\
\hline $\begin{array}{l}\text { La nueva revolución digital. De la } \\
\text { internet del consumo a la internet de } \\
\text { la Producción (CEPAL) }\end{array}$ & 2015 & $\begin{array}{l}\text { América } \\
\text { Latina }\end{array}$ & $\begin{array}{l}\text { Amplia participación de los usuarios } \\
\text { latinoamericanos en las redes sociales. } \\
\text { Cifras que superan los porcentajes de EEUU y } \\
\text { Europa. }\end{array}$ \\
\hline $\begin{array}{l}\text { Informe Universia } \\
\text { (Trabajando.com) }\end{array}$ & 2015 & $\begin{array}{l}\text { América } \\
\text { Latina }\end{array}$ & $\begin{array}{l}\text { Jóvenes perciben redes sociales como las } \\
\text { plataformas idóneas para promocionar contenidos y } \\
\text { entablar contacto con el público. } \\
\text { Consideran prioritario que las empresas posean su } \\
\text { ecosistema de redes sociales. }\end{array}$ \\
\hline $\begin{array}{l}\text { The common sense census: Media use } \\
\text { by tweens and teens (Common Sense } \\
\text { Media). }\end{array}$ & 2015 & EEUU & $\begin{array}{l}\text { Usuarios jóvenes prefieren escuchar música o ver la } \\
\text { televisión on-line antes que enviar mensajes de } \\
\text { textos o usar sus redes sociales. }\end{array}$ \\
\hline $\begin{array}{l}\text { The Modern news consumer news } \\
\text { attitudes and practices in the digital } \\
\text { era (Pew Research, Knight } \\
\text { Foundation) }\end{array}$ & 2016 & EEUU & $\begin{array}{l}\text { Incremento de los usuarios que se informan por } \\
\text { Twitter y Facebook. } \\
\text { Redes sociales se conciben como plataformas de } \\
\text { acceso a la información. }\end{array}$ \\
\hline $\begin{array}{l}\text { How millennials get news: inside the } \\
\text { habits of america's first digital } \\
\text { generation (American Press Institute) }\end{array}$ & 2016 & EEUU & $\begin{array}{l}\text { Búsqueda de información es la principal motivación } \\
\text { para acceder a Facebook en la mitad de los usuarios } \\
\text { jóvenes. }\end{array}$ \\
\hline Connected life (kANTAR TNS) & 2016 & Mundial & $\begin{array}{l}\text { Jóvenes (menores } 25 \text { años) invierten en internet } \\
\text { una media de cuatro horas y media. }\end{array}$ \\
\hline $\begin{array}{l}\text { Social media use and perceived social } \\
\text { isolation among young adults in the } \\
\text { U.S. Universidad de Pittsburgh } \\
\text { (Primack). }\end{array}$ & 2017 & EEUU & $\begin{array}{l}\text { Incremento del riesgo de aislamiento social por uso } \\
\text { de redes sociales. }\end{array}$ \\
\hline
\end{tabular}

b) Twitter: recursos expresivos. Uno de los rasgos que distingue la plataforma Twitter es que la comunicación se estructura a partir de tweets, mensajes breves que pueden incluir texto (inicialmente limitado a 140 caracteres y luego a 280), enlaces, imágenes (y video), menciones y hashtags. Las menciones son referencias directas a otros usuarios de la plataforma que se expresan con la sintaxis [@nombreusuario]. Cuando éste ocurre el usuario mencionado recibe una notificación y, por tanto, son una funcionalidad que permite llamar la atención e interactuar directamente con otros usuarios. Los hashtags 
son una convención que consiste en ubicar el carácter [\#] antes de una palabra para identificar y relacionar el contenido de un mensaje con un tema determinado o darle un énfasis particular, y un mecanismo de Twitter para coordinar conversaciones alrededor de temáticas y eventos. Permitiendo articular audiencias sin necesidad de seguir y ser seguido (Bruns y Burgess, 2015). Estos recursos estructuran a la dinámica conversacional de la plataforma y se corresponden a funcionalidades específicas. La presencia de cada una de estas convenciones ha sido el objeto de diferentes estudios que tratan de entender los usos y prácticas (Boyd et al., 2010; Gerlitz y Rieder, 2013).

c) Twitter: usos educativos. La universalización de los medios de comunicación digital en los distintos ámbitos de la vida cotidiana tan personal como profesional, exige que los diversos ámbitos formativos (obligatorios y postobligatorios) contribuyan a asegurar que toda persona participe de ellos adecuadamente y comprenda su funcionamiento para desarrollarse en ellos de forma saludable. La alfabetización mediática necesaria para navegar en los medios de comunicación digital no es sólo una necesidad para las personas especialmente digitalizadas sino también una necesidad social que va más allá de la dimensión personal. De las diversas posibilidades para desarrollar dicha competencia, se encuentra el uso del Twitter como herramienta educativa y su importancia como red en la sociedad no sólo se describe por su volumen de usuarios o presencia, sino por su relevancia en el contexto educativo -una muestra es que haya encabezado la encuesta del ranking de herramientas para educación más importantes del 2009 al 2015, elaborado por el Centre for Learning y Performance Technologies (Hart, 2019).

Muchos y muy diversos han sido los usos de Twitter en la universidad porque cada asignatura (área de estudio, contenidos, competencias, etc.) ha delimitado un contexto de enseñanza extremadamente particular y se hace difícil encontrar estudios de corte comparativo que permitan establecer unas reglas pedagógicas comunes (Carpenter y Krutka, 2014). En cierto modo, esta intensa utilización de Twitter ha promovido la necesidad de preguntarse por sus usos y efectos en la formación universitaria, y los resultados muestran una diversidad tanto de enfoques como de intenciones (Tang y Foon Hew, 2017; Veletsianos y Kimmons, 2016). A esta diversidad cabe añadirle que Twitter debe considerarse en su condición de contexto formativo informal (McPherson et al. 2015; Rehm y Notten, 2016) que dificulta el análisis de su efecto más allá del contexto del aula universitaria. Los resultados de los trabajos realizados hasta el momento invitan a seguir investigando las posibilidades del contexto educativo para identificar áreas de mejora y re-conceptualizar la pedagogía en el marco de los medios sociales (Krutka et al., 2017).

Con la voluntad de ubicar la presente investigación, se ha analizado las experiencias educativas que puedan ayudar a comprender el presente trabajo. Para ello, hemos considerado unos temas generales que ayudarán a configurar el marco de discusión, como son: el Twitter como herramienta de creación de comunidad y el Twitter como soporte para potenciar el aprendizaje. Y en un segundo momento, y de forma más específica conectando con aspectos particulares del trabajo, se ha analizado el impacto de la obligatoriedad del uso de Twitter en las asignaturas y también el uso de los hashtags como elemento educativo.

El primer grupo destaca que las experiencias muestran que el uso de Twitter potencia la comunicación y la creación de comunidad (Evans, 2014; Lord y Lomicka, 2014). Concretamente, parecería como factores determinantes que los alumnos sean responsables de la actividad (Prestridge, 2014; Tur y Marín, 2014) y el docente se implique en ello (Solmaz, 2016). Por otro lado, existe también interés en el uso de Twitter para favorecer el aprendizaje de los contenidos de la asignatura. De hecho, aunque los alumnos perciben una baja relación positiva entre Twitter y la actividad programada (Lackovic et al., 2017), se ha observado que Twitter mejora el proceso de aprendizaje (Evans, 2014), lo que a su vez mostraría una relación positiva entre su uso y el aprendizaje, como se ha reportado en otros trabajos (Junco et al., 2013; Junco et al., 2011).

Del segundo grupo, parece relevante observar qué efectos tiene Twitter en función de la forma en que se involucra al alumnado puesto que, en las experiencias mostradas aquí, Twitter se ha implementado de diversas formas y con objetivos distintos (contenido-objetivo, evaluable-no evaluable). La bibliografía muestra experiencias educativas de uso del Twitter con carácter obligatorio o siendo un elemento de evaluación de la asignatura (Bista, 2015; Domizi, 2013; Junco et al., 2013; Preston et al., 2015; West et al., 2015). El conjunto de experiencias basadas en este contexto muestran que a medida que avanzaba la 
actividad en la red,mejoraba la percepción con relación a Twitter y favorecía la conexión entre iguales. Y por último, hemos observado que el hashtag ha sido un tema de atención especial dado que agrupa contenidos y relaciona los miembros de un aula con diversas experiencias (Carpenter y Krutka, 2015; Lin et al., 2013; Rosenberg et al., 2016). En ellas, se ha observado también que si la comunidad alrededor del hashtag es fuerte, también lo será el hashtag (DeMasi et al., 2016), pero esta característica tiene su otra cara puesto que también puede colapsar el volumen de actividad sobre un tema o una actividad (Tur y Marín, 2014). Todo esto hace que sea difícil predecir el comportamiento de un hashtag y que sólo se pueda afirmar de ellos que sabemos que se comportan de forma imprevisible (Reed, 2013; Veletsianos, 2017).

\section{Método}

Se presenta un estudio descriptivo de carácter exploratorio y longitudinal que, mediante instrumentos de recogida de datos cuantitativos y cualitativos, y sobre una muestra intencional de estudiantes universitarios se ha planteado dos objetivos. En un primer momento se ha propuesto comprobar si los estudiantes priorizan las exigencias académicas cuando el microblogging forma parte de las actividades curriculares. Y, asimismo, se ha propuesto observar cómo estos estudiantes aplican los recursos expresivos de la plataforma Twitter. Para alcanzar estos objetivos se ha fijado las siguientes preguntas de investigación:

- ¿Dominan y aplican los recursos narrativos propios de la plataforma Twitter?

- ¿Dominan y aplican las directrices para la redacción de tuits?

- ¿Qué recursos han sido adoptados de forma preferente?

- ¿Cuáles son las características del uso de la plataforma en función del nivel de formalidad del encargo docente?

- ¿Cuáles son los beneficios percibidos por los estudiantes en función del nivel de formalidad del escenario educativo?

Para monitorizar y analizar cómo los jóvenes universitarios utilizan Twitter en el marco de una tarea académica se ha planteado una investigación que combina métodos cuantitativos y cualitativos (Gómez, 1990; Holsti, 1969). Se ha seleccionado una muestra de carácter intencional, integrada por el alumnado de tres asignaturas de dos universidades diferentes que han sido anonimizadas. Además, se ha considerado importante que tal muestra integrara dos materias del ámbito de la comunicación (Periodismo y Comunicación audiovisual) y otra de un ámbito alejado como la Formación del profesorado. En los tres casos, el alumnado estaba integrado por estudiantes (hombres y mujeres) de entre 19 a 25 años de edad que en total sumaban 317. En este contexto, en cada caso, se definió una actividad académica diferente vinculada con el uso de Twitter. Todos los encargos compartían la obligatoriedad de publicar contenidos en la citada plataforma con un conjunto de hashtags creados ad hoc por cada docente y adaptados a la temática de la asignatura en cuestión.

Figura 1. Diseño de la muestra: complementariedad y alcance

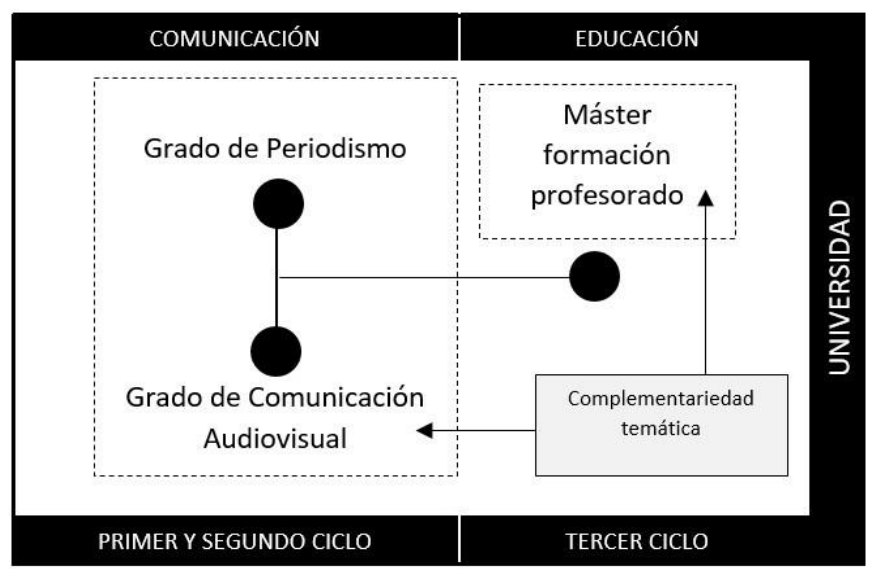


Se han recolectado todos los tuits de los estudiantes que tuvieran los hashtags elegidos al efecto, de forma automatizada y no intrusiva mediante el software DMI-TCAT. Una herramienta diseñada para almacenar y analizar tuits con el propósito de llevar a cabo investigaciones en el ámbito de las ciencias sociales y humanas (Borra y Rieder, 2014). El DMI-TCAT incorpora todos los tuits en una base de datos que luego puede ser explotada para extraer y analizar el contenido de los tuits. La investigación ha utilizado tres programas informáticos para la creación de las hojas de cálculo y en la visualización de gráficos, como son Excel, Tableau y Google Spreadsheets.

El grupo A estuvo integrado por 59 estudiantes de una asignatura de primer semestre del máster de Formación del profesorado. En la actividad definida para este grupo, Twitter fue un elemento de evaluación, siendo una estrategia de desarrollo de la competencia mediática. En este sentido, se animó a los estudiantes a darse de alta y utilizar esta plataforma como espacio informal de aprendizaje de los contenidos educativos del máster, pero también como espacio formal de aprendizaje por estar incluido el Twitter en la evaluación de la asignatura. Para ello, se utilizó el hashtag que aglutina toda la actividad del máster y se evaluó la actividad al final del semestre mediante una rúbrica que incluía, ente otros, la cantidad de tuits, la creación de comunidad y el valor del contenido.

El grupo B estuvo integrado por 78 estudiantes de una asignatura de segundo semestre del grado de Comunicación audiovisual. En este caso se animó a los estudiantes a publicar tuits con el hashtag de la asignatura de manera informal y también se utilizó el hashtag para los ejercicios de evaluación continua. En total se llevaron a cabo cuatro ejercicios en los estudiantes que eran evaluados teniendo en consideración la correcta aplicación de buenas prácticas que incidían tanto en la redacción de los tuits como en la utilización de recursos multimedia (imágenes y enlaces), así como los objetos propios de la plataforma (menciones y hashtags).

El grupo C estuvo integrado por 180 estudiantes de una asignatura de primer semestre del grado de Periodismo. En el marco de la misma, los estudiantes debían realizar la cobertura de una jornada monográfica, integrada por varias conferencias y mesas redondas, utilizando un hashtag creado ad hoc para la actividad. Durante un período aproximado de 8 horas (abarcando las sesiones de mañana y tarde), los alumnos debían cubrir cada una de las intervenciones utilizando Twitter. Los parámetros de evaluación se centraban en la capacidad de síntesis de los tuits generados y la adaptación de los mismos a las particularidades de la redacción ciberperiodística. No se estableció ningún indicador, a modo de exigencia, relativo a la cantidad de mensajes que debían ser publicados.

La recolección mediante el software DMI-TCAT de todos los tweets que incluían alguno de los hashtags creados arrojó una muestra compuesta por 10291 tweets publicados por 817 usuarios de Twitter distintos. El número es sensiblemente superior al de estudiantes que participaron en la actividad docente en la medida en que la actividad de los estudiantes generó que otros usuarios de la plataforma también participaran aplicando los mismos hashtags. Estos tweets fueron analizados y contabilizados con dicha herramienta que permite identificar los objetos mediáticos (como hashtags, menciones, direcciones URL e imágenes, entre otros elementos) y, por tanto, analizar los recursos expresivos utilizados por el alumnado en cada una de las actividades docentes. El análisis cuantitativo de estos indicadores se ha complementado con la consulta de los tuits para poder contextualizar e interpretar los resultados.

Adicionalmente, con posterioridad a las actividades académicas se llevaron a cabo 3 grupos focales (uno por cada asignatura), con entre 4 y 6 estudiantes, en los que se siguió un guion que tenía por objetivo que los participantes definieran la plataforma Twitter, sus potencialidades, los elementos a tener en cuenta para crear contenidos dentro y fuera del ámbito académico, y las pautas aplicadas en la inclusión de los distintos recursos que posibilita la plataforma, confiriendo una especial atención al uso de hashtags. En total se han llevado a cabo tres encuentros con los alumnos de cada una de las asignaturas antes mencionadas. 


\section{Resultados}

El proceso de recolección de tuits arrojó una muestra de 10291 tuits publicados por 816 usuarios distintos. Tal como se aprecia en la Tabla 2 el número de tuiteros supera en todos los casos el número de estudiantes en cada una de las asignaturas. Este hecho se atribuye a la capacidad que tuvieron los estudiantes de involucrar a otros usuarios de la plataforma en el uso de los hashtags vinculados a las actividades docentes, sea en forma de retuits, respuestas o tuits originales. Los datos también permiten observar cómo la actividad docente donde la publicación de contenidos presentaba una mayor formalización (Grupo A) fue también la que generó un mayor número de tuits (en cifras absolutas y relativas) e involucró a más usuarios externos a la asignatura. Aun así, los tres enfoques docentes incrementan significativamente el número de tuiteros involucrados en el hashtag.

Tabla 2. Tuits y tuiteros

\begin{tabular}{lcccc}
\hline Grupo & $\begin{array}{c}\text { Núm. } \\
\text { de tuits }\end{array}$ & $\begin{array}{c}\text { Núm. } \\
\text { de alumnos }\end{array}$ & $\begin{array}{c}\text { Núm. } \\
\text { de tuiteros }\end{array}$ & $\begin{array}{c}\text { Tuits } \\
\text { por tuitero }\end{array}$ \\
\hline A & 5834 & 59 & 374 & 15.59 \\
B & 1926 & 78 & 172 & 11.19 \\
C & 2531 & 180 & 270 & 9.37 \\
Total & 10291 & 317 & 816 & 12.6 \\
\hline
\end{tabular}

Del conjunto de tuits que se incorporaron a la base de datos se desprende que los estudiantes complementaron el contenido textual con la inserción de menciones, hashtags, imágenes y enlaces de forma desigual. En la Figura 1 se observa que, de los tres grupos, el B fue el que utilizó de forma más recurrente y equilibrada las distintas modalidades para enriquecer los contenidos. Este hecho es atribuible a que en el planteamiento de los ejercicios se hacía especial hincapié en explotar las posibilidades de la plataforma para enriquecer el contenido de los tuits. Además, el grupo C se distingue por un uso intensivo de las menciones (presentes en un 76.5\% de los tuits). Este resultado podría estar estrechamente ligado a las especificidades de la tarea, que consistía en la narración en tiempo real de una conferencia en la que los estudiantes recurrían a la mención para atribuir la autoría de las distintas intervenciones de los conferenciantes. El grupo A destaca, en cambio, por la inserción de un elevado número de enlaces (un 68\%) en los tuits que se puede relacionar con la práctica de compartir contenidos de internet relacionados con la asignatura y su voluntad de desarrollar contenido educativo.

Figura 2. Uso de recursos no textuales

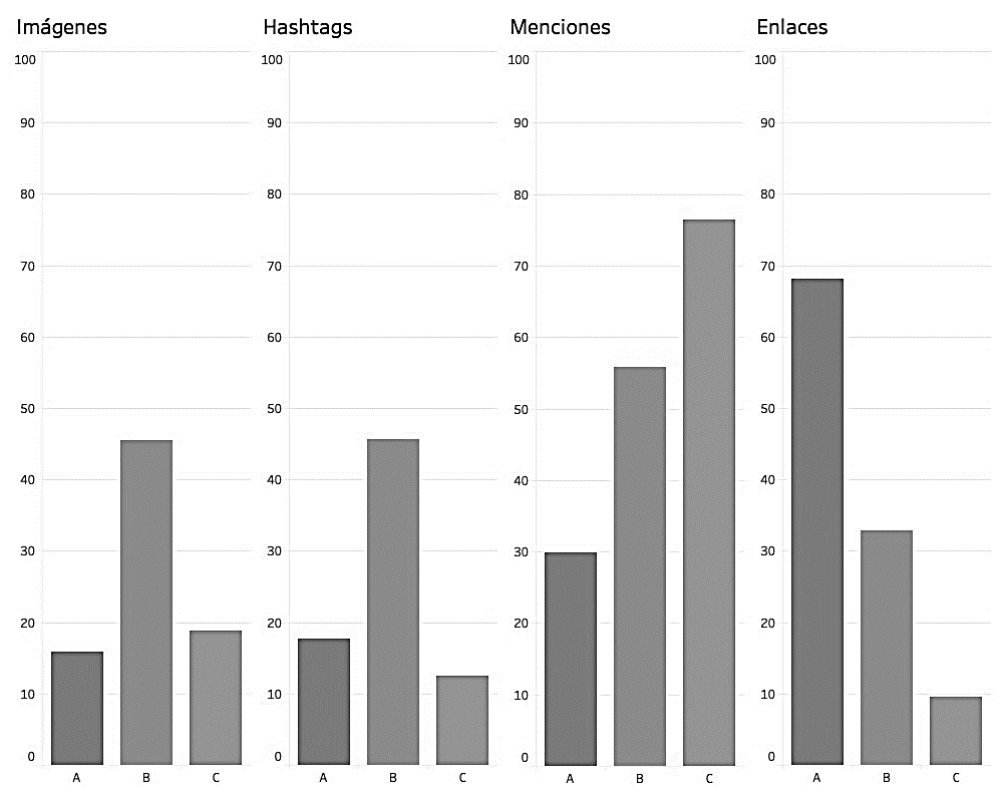


Los resultados de los grupos focales permiten, entre otros aspectos, concluir que la concepción de Twitter por parte del alumnado (ver Tabla 3) incide en la caracterización de Twitter como un espacio para la polémica y la discusión encendida ("batalla", "irrespeto"), la conversación banal y la propagación de la desinformación ("rumores", "cotilleo", "cachondeo"), informarse y formarse ("actualidad", "aprendizaje", "fuente de información", "oportunidad" o "descubrir"). Existe, en este sentido, una concepción de la herramienta que abarca tanto las fortalezas como los principales problemas vinculados con esta red de microblogging y que reconoce el papel crucial que juega la plataforma dentro de un ecosistema de medios híbrido ("Twitter es para encontrar titulares sobre la actualidad y después informarse. Difícilmente entraré en un periódico si antes no veo el titular en Twitter").

Tabla 3. Twitter: aspectos definitorios

\begin{tabular}{l}
\hline Concepciones de Twitter \\
"Rumores". "Cotilleo". "Batalla". "Instante". "Actualidad". "Titulares". "Trending Topics". "Irrespeto". \\
"Aprendizaje". "Fuente de información". "Oportunidad". "Entretenimiento". "Descubrir". "Cachondeo" \\
\hline
\end{tabular}

Respecto a los parámetros de escritura prioritarios en la concepción y escritura de un tuit, el alumnado destaca aspectos vinculados con la inmediatez de esta plataforma y la naturaleza multimedia de la misma (texto, fotografías, videos y enlaces), así como la necesidad de velar por la corrección gramatical. Además, como se observa en la Tabla 4, más allá de los aspectos puramente formales, se alude al enfoque de los contenidos, especialmente al impacto que suelen alcanzar los tuits de índole política.

Tabla 4. Parámetros formales para la escritura de tuits

\begin{tabular}{l}
\hline Formalidad en Twitter \\
\hline "Directo". "Inmediato". "Corto". "Actual". "Rápido" \\
"Debe ser corto, pero intenso" \\
"No hacer faltas de ortografía" \\
"Utilizar enlaces" \\
"No posicionarse políticamente" \\
"Aprovechar el aspecto visual" \\
"Que sea ingenioso y que lleve un hashtag para que llegue a más gente" \\
\hline
\end{tabular}

El alumnado no coincide en identificar cuál es la función principal y la utilidad a nivel informativo que poseen los hashtags. Existe un consenso en señalar que estas etiquetas orientan o sitúan el contenido, pero existen discrepancias sobre su carácter promocional y su esencia puramente informativa u organizativa. De este modo, se detecta una cierta confusión terminológica alrededor de uno de los elementos que conforman la idiosincrasia de esta plataforma digital.

Tabla 5. ¿Qué aspectos definen un hashtag?

\begin{tabular}{l}
\hline El hashtag \\
\hline "Es una orientación" \\
"Es una cabecera" \\
"Es una guía" \\
"Es un concepto" \\
"Es una estrategia de marketing" \\
"Es una temática" \\
"Es el lugar donde ir para encontrar una información específica" \\
"Agrupan los tuits sobre un mismo tema" \\
"Sirven para hacer campaña a favor de una idea" \\
"Es como una guía turística para moverse por Twitter" \\
\hline
\end{tabular}

El alumnado coincide en señalar que la forma de redactar sus tuits cambia por completo cuando están en un ámbito académico respecto a cómo escribirían ese mismo contenido fuera de él ("el escenario académico te obliga a hablar de otra manera"); destacan una mayor formalidad y reflexión cuando se publica contenido en el contexto de las asignaturas ("para la asignatura teníamos que pensar mucho más") 
y el uso de un mayor repertorio de recursos narrativos ("raramente utilizo imágenes cuando lo hago para uso personal"). Los estudiantes apuntan incluso que disponen de cuentas diferentes según el uso sea académico o no ("son temas diferentes y por eso uso diferentes cuentas"). En la mayoría de los casos el alumnado indica que desea mantener su espacio personal alejado de la actividad académica ("es una manera de protegerte" o "no les interesa mi vida").

Por otro lado, los alumnos concluyen que no utilizan un hashtag definido en un ámbito académico cuando ha finalizado el evento o actividad lectiva en el marco de la cual fue creada. Por un lado, aluden a la gran cantidad de etiquetas que se generan en el marco de sus estudios ("hay muchos"), y por otro, insisten en que se trata de actividades regladas ("es algo que te han impuesto"); y, por último, apuntan que su tiempo de vida es muy efímero debido a que se enmarcan en actos muy atomizados ("quedan rápidamente obsoletos").

Sin embargo, resulta importante señalar que los alumnos destacan que el uso de Twitter en el escenario académico (cobertura de actos, especialmente) les ha servido para conocer esta herramienta o profundizar en el uso de la misma ("yo antes no sabía que se podían publicar gifs"). Este tipo de reflexión ha estado presente en el conjunto de los grupos focales realizados ("al principio me vi forzado a usar Twitter, pero ahora tengo una visión diferente y positiva". "El uso de Twitter en el ámbito académico ha reafirmado mi opinión sobre la herramienta como un lugar de oportunidades donde debo potenciar mi perfil". "En una entrevista de trabajo me hicieron escribir una noticia y un tuit para darla a conocer y me acordé de lo que habíamos visto en clase).

\section{Discusión y conclusiones}

La investigación permite una interesante discusión alrededor de diferentes ámbitos temáticos. Por un lado, desde una óptica educativa Carpenter y Krutka (2014) apuntaban a la dificultad de establecer reglas pedagógicas comunes dada la diversidad de propuestas docentes que habían estudiado el impacto de Twitter en la formación universitaria. El presente trabajo, por el contrario, muestra que incluso en la diversidad de grupos clase y tareas, los estudiantes priman las directrices académicas. Este aspecto queda verificado al analizar la estructura y forma de los tuits. A su vez colisiona con la consideración de Twitter como un contexto formativo informal (McPherson et al., 2015; Rehm y Notten, 2016) dada la formalidad en el comportamiento del alumnado mostrada en los mensajes compartidos y, además, en su percepción sobre cómo debían comportarse en el marco del encargo docente.

Por otro lado, como ya apuntaban Evans (2014) y Lord y Lomicka (2014), el hecho que de una población inicial de 317 sujetos se hayan recolectado datos de 816 tuiteros, describe un uso de Twitter que potencia la comunicación y la creación de comunidad más allá de la actividad académica. A partir de estos resultados parecería posible regular el comportamiento de los estudiantes con relación a Twitter mediante la forma de la tarea o del encargo. Sin embargo, resultaría igualmente inviable controlar la actividad generada en el ciberespacio a partir de dicha actividad. Esta última característica coincide con los planteamientos de Veletsianos (2017) al expresar la imprevisibilidad del comportamiento de los hashtags en la red social Twitter aun habiendo una tarea determinada. En cierto modo, este análisis nos conduciría a pensar que el máximo éxito (concebido, especialmente, como compromiso y participación del alumnado) demanda de un grado detallado de especificación de las propuestas formativas que se presentan al alumnado.

Estas primeras conclusiones contrastan con la idiosincrasia horizontal y anárquica de esta plataforma. Sin embargo, resultan de gran utilidad para corroborar su carácter colaborativo, horizontal y participativo. A su vez, los resultados del estudio respaldan las propuestas y postulados de autores como Barabási y Bonabeau (2003), Roblyer et al. (2010) y Singh et al. (2015), entre otros, que han insistido en la importancia de contemplar las potencialidades de las plataformas colaborativas (especialmente, Twitter) en el diseño de actividades y procesos formativos a nivel general. A ello se suma que el alumnado coincide en destacar que el desarrollo de actividades lectivas en Twitter les ha permitido profundizar en el conocimiento y manejo de la herramienta, e incluso en apreciar su potencial en su desempeño laboral. 
Por otro lado, en otro foco de discusión, la investigación desarrollada permite concluir que la plataforma Twitter como recurso educativo destaca por involucrar un mayor número de usuarios que los que estrictamente aglutinaba la actividad o el ejercicio académico diseñado. Este aspecto, en la línea de lo señalado por Boyd (2007) y O'Keeffe y Clarke-Pearson (2011), incide en las oportunidades que los usuarios pueden obtener de los medios sociales, enfatiza la esencia líquida de la herramienta, al tiempo que introduce importantes desafíos en el ámbito formativo y a nivel investigativo. Este aspecto está vinculado con el valor conferido a la participación en Twitter, como apuntaban los mismos alumnos en los grupos focales, que inaugura oportunidades de desarrollo tanto a nivel personal como laboral.

La inmediatez y celeridad de los intercambios comunicativos actuales son los aspectos que más determinan el proceso que los jóvenes universitarios aplican en la concepción y escritura de sus mensajes, incluso en aquellos que tienen origen en la universidad. Esta conclusión engarza directamente con los estudios señalados de McPherson et al. (2015) y Rehm y Notten (2016), que incidían en la idiosincrasia informal, dialógica y horizontal de Twitter como plataforma comunicativa de carácter colaborativo.

A partir de los trabajos de Evans (2014) y Lord y Lomicka (2014), que enfatizan la capacidad de Twitter para generar comunidades de diferente tipología y favorecer la participación de sus integrantes, resultaría de interés el desarrollo de futuras investigaciones en este campo, sobre cómo los estudiantes transforman los aspectos formales de producción de contenidos y apuestan por una mayor formalidad y reflexión, en el marco de encargos o actividades de naturaleza lectiva. Estas propuestas coinciden con los postulados de Solmaz (2016), Prestridge (2014) y Tur y Marín (2014) que abogan por fomentar el liderazgo del propio alumnado en este tipo de propuestas formativas. La conformación de ecosistemas digitales paralelos y autónomos (académico versus no académico), justificados por una voluntad manifiesta de querer preservar el espacio personal, demanda de nuevos trabajos que indaguen los porqués que respaldan este tipo de percepciones y usos.

A modo de conclusión final, este trabajo se adentra en el contexto informal de Twitter como herramienta docente corroborando las reflexiones de Hart (2019) y Evans (2014) sobre su potencial educativo. En este sentido, es especialmente relevante que el docente tenga consciencia de que el alumnado prioriza las directrices académicas, aun en la informalidad propia de Twitter; y que aun teniendo la formalidad del encargo académico, la actividad trasciende el espacio docente de la asignatura. Twitter como herramienta educativa se muestra, pues, como una plataforma que aun iniciándose dentro del aula sale de ella, formando al estudiante en la superposición de lo formal y lo informal.

\section{Referencias}

Barabási, A. L. y Bonabeau, E. (2003). Scale-free networks. Scientific American, 288(5), 60-69. https://doi.org/10.1038/scientificamerican0503-60

Bista, K. (2015). Is Twitter a pedagogical tool in higher education? Perspectives of education graduate students. Journal of the Scholarship of Teaching and Learning, 15(2), 83.

https://doi.org/10.14434/josotl.v15i2.12825

Borra, E. y Rieder, B. (2014). Programmed method: Developing a toolset for capturing and analyzing tweets. Aslib Journal of Information Management, 66(3), 262-278. https://doi.org/10.1108/AJIM-09-2013$\underline{0094}$

Boyd, D. (2007). Why youth (heart) social network sites: The role of networked publics in teenagers social life. En D. Buckingham (Ed.), Youth, identity, and digital media (pp. 119-142). MacArthur Foundation. https://ssrn.com/abstract=1518924

Boyd, D., Golder, S. y Lotan, G. (2010). Tweet, tweet, retweet: Conversational aspects of retweeting on Twitter. 43rd Hawaii International Conference on System Sciences, 1-10.

https://doi.org/10.1109/HICSS.2010.412 
Bruns, A. y Burgess, J. (2015). Twitter hashtags from ad hoc to calculated publics. En N. Rambukkana (Ed.), Hashtag publics: The power and politics of discursive networks (pp. 13-28). https://doi.org/10.3726/978-1$\underline{4539-1672-8}$

Carpenter, J. P. y Krutka, D. G. (2014). How and why educators use Twitter: A survey of the field. Journal of Research on Technology in Education, 46(4), 414-434. https://doi.org/10.1080/15391523.2014.925701

Carpenter, J. P. y Krutka, D. G. (2015). Engagement through microblogging: educator professional development via Twitter. Professional Development in Education, 41(4), 707-728.

https://doi.org/10.1080/19415257.2014.939294

Castells, M. (2003). La galaxia internet. Random House.

ComScore. (2016). IMS Mobile in LatAm Study (2a. ed.). https://www.imscorporate.com/news/EstudioscomScore/IMS-Mobile-Study-Septiembre2016.pdf

DeMasi, O., Mason, D. y Ma, J. (2016). Understanding communities via hashtag engagement: A clustering based approach. Actas 10th International AAAI Conference on Web and Social Media (ICWSM), 102-111. The AAAI Press.

Domizi, D. (2013). Microblogging to foster connections and community in a weekly graduate seminar course. TechTrends, 57(1), 43-51.

Evans, C. (2014). Twitter for teaching: Can social media be used to enhance the process of learning? British Journal of Educational Technology, 45(5), 902-915. https://doi.org/10.1111/bjet.12099

Galindo, J. (2010). La internet y sus redes sociales. Comunicología e ingeniería en comunicación social de un fenómeno aún emergente. Razón y Palabra, 15(71).

http://www.razonypalabra.org.mx/N/N71/index.html

Gerlitz, C. y Rieder, B. (2013). Mining one percent of Twitter: Collections, baselines, sampling. M/C Journal, 16(2). http://journal.media-culture.org.au/index.php/mcjournal/article/view/620

Gómez, J. (1990). Metodología de encuestas por muestreo. En J. Arnau, M. T. Anguera, y J. Gómez (Eds.), Metodología de la investigación en ciencias del comportamiento (pp. 237-310). Universidad de Murcia.

Hart, J. (2019). Top 200 tools for learning 2018. https://www.toptools4learning.com/home/

Holsti, O. R. (1969). Content analysis for the social sciences and humanities. Addison-Wesley.

IAB España. (2019). Estudio anual de redes sociales 2019. https://iabspain.es/estudio/estudio-anual-deredes-sociales-2019/

Jones, C., Ramanau, R., Cross, S. y Healing, G. (2010). Computers y education net generation or digital natives: Is there a distinct new generation entering university? Computers y Education, 54(3), 722-732.

https://doi.org/10.1016/j.compedu.2009.09.022

Junco, R., Elavsky, C. M. y Heiberger, G. (2013). Putting Twitter to the test: Assessing outcomes for student collaboration, engagement and success. British Journal of Educational Technology, 44(2), 273-287.

https://doi.org/10.1111/j.1467-8535.2012.01284.x

Junco, R., Heiberger, G. y Loken, E. (2011). The effect of Twitter on college student engagement and grades. Journal of Computer Assisted Learning, 27(2), 119-132. https://doi.org/10.1111/j.13652729.2010.00387.x 
KANTAR TNS. (2017). Connected Life. How connectivity is reshaping consumers, connections, content and commerce. https://bestmediainfo.com/wp-content/uploads/2016/11/TNS-digital.pdf

Krutka, D., Nowell, S. y Whitlock, A. M. (2017). Towards a social media pedagogy: Successes and shortcomings in educative uses of Twitter with teacher candidates. Journal of Technology and Teacher Education, 25(2), 215-240. https://www.learntechlib.org/p/161880/

Lackovic, N., Kerry, R., Lowe, R. y Lowe, T. (2017). Being knowledge, power and profession subordinates: Students' perceptions of Twitter for learning. Internet and Higher Education, 33, 41-48.

https://doi.org/10.1016/j.iheduc.2016.12.002

Lin, M.-F. G., Hoffman, E. S. y Borengasser, C. (2013). Is social media too social for class? A case study of Twitter use. TechTrends, 57(2), 39-45. https://doi.org/10.1007/s11528-013-0644-2

Lord, G. y Lomicka, L. (2014). Twitter as a tool to promote community among language teachers. Journal of Technology and Teacher Education, 22(2), 187-212. http://www.editlib.org/p/49768

McPherson, M., Budge, K. y Lemon, N. (2015). New practices in doing academic development: Twitter as an informal learning space. International Journal for Academic Development, 20(2), 126-136.

https://doi.org/10.1080/1360144X.2015.1029485

O'Keeffe, G. S. y Clarke-Pearson, K. (2011). Clinical Report -the impact of social media on children, adolescents, and families. American Academy of Pediatrics, 127(4), 800-804.

https://doi.org/10.1542/peds.2011-0054

Ofcom. (2015). Public Service Broadcasting in the Internet Age. Ofcom's Third Review of Public Service Broadcasting. https://www.ofcom.org.uk/ data/assets/pdf file/0025/63475/PSB-statement.pdf

Pérez, J. M. y Tejedor, S. (Eds.). (2016). Ideas para aprender a aprender manual de innovación educativa y tecnología. UOC.

Preston, J. P., Jakubiec, B. A. E., Jones, J. y Earl, R. (2015). Twitter in a bachelor of education course: Student experiences. Learning Landscapes, 8(2), 301-317. https://doi.org/10.36510/learnland.v8i2.710

Prestridge, S. (2014). A focus on students' use of Twitter -their interactions with each other, content and interface. Active Learning in Higher Education, 15(2), 101-115. https://doi.org/10.1177/1469787414527394

Primack, B., Shensa, A., Sidani, J., Whaite, E., Lin, L., Rosen, D., Colditz, J., Radovic, A. y Miller, E. (2017). Social media use and perceived social isolation among young adults in the U.S. American Journal of Preventive Medicine, 53(1), 1-8. https://doi.org/10.1016/i.amepre.2017.01.010

Reed, P. (2013). Hashtags and retweets: Using Twitter to aid community, communication and casual (informal) learning. Research in Learning Technology, 21, 1-21. https://doi.org/10.3402/rlt.v21i0.19692

Rehm, M. y Notten, A. (2016). Twitter as an informal learning space for teachers!? The role of social capital in Twitter conversations among teachers. Teaching and Teacher Education, 60, 215-233.

https://doi.org/10.1016/j.tate.2016.08.015

Rideout, V. (2015). The common sense census: Media use by tweens and teens.

https://www.commonsensemedia.org/sites/default/files/uploads/research/census researchreport.pdf

Roblyer, M. D., McDaniel, M., Webb, M., Herman, J. y Witty, J. V. (2010). Findings on Facebook in higher education: A comparison of college faculty and student uses and perceptions of social networking sites. Internet and Higher Education, 13(3), 134-140. https://doi.org/10.1016/i.iheduc.2010.03.002 
Rosenberg, J. M., Greenhalgh, S. P., Koehler, M. J., Hamilton, E. R. y Akcaoglu, M. (2016). An investigation of State Educational Twitter Hashtags (SETHs) as affinity spaces. E-Learning and Digital Media, 13(1-2), 2444. https://doi.org/10.1177/2042753016672351

Scolari, C. A. (2012). Media ecology: Exploring the metaphor to expand the theory. Communication Theory, 22(2), 204-225. https://doi.org/10.1111/j.1468-2885.2012.01404.x

Scolari, C. A. (2013). Media evolution: Emergence, dominance, survival, and extinction in the media ecology. International Journal of Communication, 7, 1418-1441. https://ijoc.org/index.php/ijoc/article/view/1919

Singh, J., Grizzle, A., Yee, J. y Culver, S. H. (Eds.). (2015). Media and information literacy for the sustainable development goals. NORDICOM.

Solmaz, O. (2016). \#Beyond140: Helping pre-service teachers construct a community of inquiry on Twitter. Turkish Online Journal of Educational Technology, 15(4), 1-15.

https://Files.eric.ed.gov/fulltext/EJ1117634.pdf

Tang, Y. y Foon Hew, K. (2017). Using Twitter for education: Beneficial or simply a waste of time? Computers \& Education, 106, 97-118. https://doi.org/10.1016/j.compedu.2016.12.004

Tur, G. y Marín, V. I. (2014). Enhancing learning with the social media: Student teachers' perceptions on Twitter in a debate activity. Journal of New Approaches in Educational Research, 4(1), 46-43.

https://doi.org/10.7821/naer.2015.1.102

Veletsianos, G. (2017). Three cases of hashtags used as learning and professional development environments. TechTrends, 61(3), 284-292. https://doi.org/10.1007/s11528-016-0143-3

Veletsianos, G. y Kimmons, R. (2016). Scholars in an increasingly open and digital world: How do education professors and students use Twitter? Internet and Higher Education, 30, 1-10.

https://doi.org/10.1016/j.iheduc.2016.02.002

West, B., Moore, H. y Barry, B. (2015). Beyond the Tweet: Using Twitter to enhance engagement, learning, and success among first-year students. Journal of Marketing Education, 37(3), 160-170.

https://doi.org/10.1177/0273475315586061 